\title{
Psychobiologic Correlates of Treatment Response in Schizophrenia
}

Jeffrey A. Lieberman, M.D., Jose Ma Alvir, Dr.P.H., Amy Koreen, M.D., Steven Geisler, M.D., Miranda Chakos, M.D., Brian Sheitman, M.D., and Margaret Woerner, Ph.D.

In studies conducted on largely treatment naive patients in their first episode of psychosis, we have found that treatment outcome is quite good and that most patients recover or at least achieve a substantial degree of symptom remission. However, over the course of their illness and in the context of subsequent psychotic episodes, they may experience some decrease in their treatment response from illness progression. In addition, the heterogeneity of treatment outcome is associated with specific clinical (gender, primary negative symptoms of the deficit state, duration of psychosis) and biological variables ( $p H V A$, ventricular volume). It is unclear whether these variables represent aspects of discrete subtypes of schizophrenia or dimensional measures of pathology within the broad context of a unitary disease entity. [Neuropsychopharmacology 14:13S-21S, 1996]
KEY WORDS: Schizophrenia; Antipsychotic Drugs; Outcome; Brain morphology; Dopamine; Deterioration

It is widely acknowledged that the treatment response and long-term outcome of schizophrenia are heterogeneous (McGlashan 1988). Efforts to identify features of the illness or specific biologic measures that are predictive of outcome have been a major goal of research (Lieberman and Sobel 1993; Lieberman and Koreen 1993). Although some variables have been shown to correlate with outcome, they account for only a limited proportion of the outcome variance and have not been consistently replicated. Thus, efforts to reduce the heterogeneity of schizophrenia by identifying predictors of

From the Department of Psychiatry, Albert Einstein College of Medicine, Hillside Hospital, Long Island Jewish Medical Center, Glen Oaks, New York.

Address correspondence to: Jeffrey A. Lieberman, M.D., Hillside Hospital, Long Island Jewish Medical Center, 75-59 263rd Street, Glen Oaks, NY 11004.

This article was presented at the integrated symposium "A New Understanding: Neurological Basis and Long-Term Outcome of Schizophrenia" chaired by Herbert Y. Meltzer and Leif $\mathrm{H}$. Lindström at the CINP Congress, June 28, 1994, in Washington, DC. treatment outcome and illness course have not been entirely successful.

One reason that may have constrained the ability of previous studies to identify predictors of outcome was the fact that their samples have included patients at different stages of their illness. Another reason may have been that studies involved largely cross-sectional assessments that were correlated retrospectively with the patients' illness and treatment histories.

We have attempted to address the issue of heterogeneity of treatment response and outcome in schizophrenia by studying patients in their first episode of illness. First-episode patients offer some advantages in that they are relatively homogeneous in terms of their stage of illness, they are free of the effects of prior treatment exposure (which can produce confounding effects on variables being examined), and they can be followed prospectively over the critical early stages of their illness to determine how measures correlate with illness progression and whether those measures change over time. The results of this work have been previously reported (Bilder et al. 1994; Chakos et al. 1992, 1994; Degreef et al. 1992; Koreen et al. 1994a,b, 1993; Lieberman et al. 1992 a,b, 1993a,b; Loebel et al. 1992; Mayerhoff et al. 1994; Szymanski et al. 1995). 


\section{METHODS}

The complete methods of the study have been previously reported in detail (Lieberman et al. 1992, 1993a, b). Briefly, patients were ascertained when admitted to the hospital for their first episode of psychosis. After baseline assessments for psychopathology, neurologic and cognitive status, brain morphology (using magnetic resonance imaging) (MRI) and measures of central nervous system (CNS) dopamine (DA) activity (including growth hormone $(\mathrm{GH})$ secretory levels, plasma homovanillic acid (pHVA), and behavioral response to methylphenidate), patients received controlled treatment within a standardized protocol to a point of remission. Patients were then followed for up to 5 years during which time the clinical and biologic assessments were repeated at specific time intervals including performing the MRIs at 18-month intervals. If patients relapsed they were retreated with the same regimen to which they responded during their first (or prior) episode and in the context of the standardized protocol.

\section{RESULTS}

The sample $(N=70)$ was $56 \%$ male, had a mean \pm SD age of $24.3 \pm 6$ years, was $44 \%$ white, $32 \%$ black, $17 \%$ hispanic, and $7 \%$ asian. There was a range of socioeconomic classes and educational levels, but a predomi- nance of middle class and below. Patients had high levels of psychopathology at study entry; they were severely ill with a mean \pm SD CGI of $5.6 \pm 1.2$ and GAS of $24.5 \pm 9.3$. The RDC diagnoses based upon SADS interviews were as follows: schizophrenia, $N=54(19 \%$ paranoid, $54 \%$ undifferentiated, $3 \%$ disorganized, $1 \%$ catatonic subtypes); schizoaffective disorder, mainly schizophrenic $N=16$ ( $7 \%$ manic, $16 \%$ depressed subtypes). A minority of patients had received pharmacologic treatment prior to index hospital admission: $70 \%$ had no prior neuroleptics; $19 \%$ had less than 2 weeks of medication exposure ( $\bar{x}=5$ days); and $11 \%$ had between 2- and 12-week exposure ( $\bar{x}=6.8$ weeks). Patients were off all medication for 14 days before baseline procedures.

Following completion of baseline assessments, patients were treated according to a standardized algorithm beginning with fluphenazine $20 \mathrm{mg} /$ day for 6 weeks; after at least 6 months of treatment with different doses and drug types, patients could ultimately receive clozapine on the basis of treatment refractoriness. The average antipsychotic drug dose in fluphenazine equivalents during the entire acute treatment period for the sample was $24( \pm 15) \mathrm{mg} /$ day. The mean $\pm \mathrm{SE}$ and median $\pm \mathrm{SE}$ times to recovery for the sample were $36 \pm$ 7.8 weeks and $11 \pm 1.4$ weeks. The time course and rate of remission are shown in Figure 1. Eleven patients $(16 \%)$ did not recover from their first episode. Seven of these patients were considered treatment refractory;

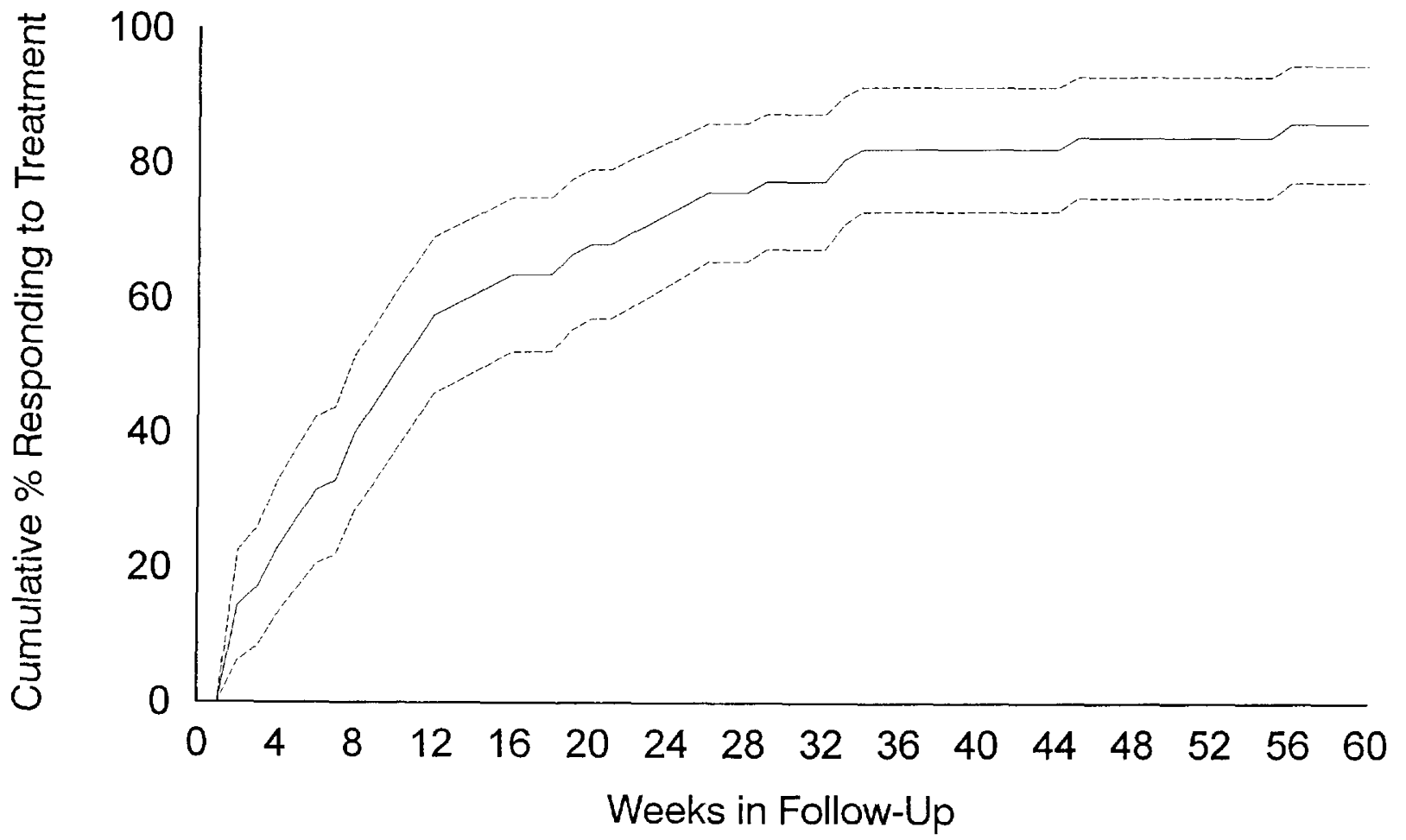

Figure 1. Cumulative percentage of first-episode patients responding to treatment. Dotted lines represent $95 \%$ confidence intervals. 
they failed to improve after all phases of the treatment algorithm and almost 1 year of treatment and were treated with clozapine. The remaining four patients were still undergoing acute treatment. The high recovery rate was not surprising for young first-episode patients. However, the time to remission was surprisingly long. We believe this may be due in part to our conservative criteria for remission. Further, some patients had been ill for long periods prior to treatment.

The degree of remission was evaluated in 66 patients, excluding the four patients who were still undergoing acute treatment as of the cutoff date. Seventy-four percent were considered to be fully remitted (no residual symptoms and return to premorbid level of function), $12 \%$ were considered to be partially remitted (mild residual positive or moderate negative symptoms), and $14 \%$ were considered to be not remitted.

Timing of onset of illness was classified in two ways: (1) the time at which the patient first exhibited behavioral changes, which (in retrospect) appeared to have been related to his/her illness; and (2) the time at which the patient first developed formal psychotic symptoms. By these definitions patients had been ill for 151 (177) weeks and $52(82)$ weeks respectively. It was surprising that many patients had active psychotic symptoms for so long before coming to treatment. This issue is of considerable public health significance.

The effect on time to remission of pretreatment variables including duration of illness prior to study entry, diagnosis and gender was determined using a Cox multiple regression analysis. As has been previously described in the literature, males took longer to remit (mean/median 48/12 weeks vs $17 / 9$ weeks Mantel Cox = $2.7, p=.1)$ and achieved a lower level of outcome than females $\left(\chi^{2}=5.7, p=.13\right)$. Similarly, schizoaffective disorder was associated with better treatment response, but this failed to reach even the trend level of statistical significance (discussed later). However, duration of psychotic symptoms was the only variable significantly associated with time to remission after the variance accounted for by the other variables was removed (Cox stat $=4.4, p<.04$ ) with longer pretreatment duration being associated with longer time to remission (see Figure 2). These results are consistent with previous reports (May et al. 1982; Crow et al. 1986; Wyatt 1991) that found duration of illness prior to treatment to be correlated with poor outcome. They suggest that there is an active morbid process that occurs during periods of acute symptoms that, if not counteracted, produces some lasting effect and can impair patients' capacity to respond to treatment.

Patients had substantial psychopathology at baseline including positive and negative symptoms. The effects of diagnosis and psychopathology on outcome were examined. Patients with schizoaffective disorder remitted more quickly (mean $/$ median $=12 / 11$ weeks) and achieved a higher level of global outcome than schizophrenics $($ mean $/$ median $=42 / 10$ weeks). (Mantel Cox $=$

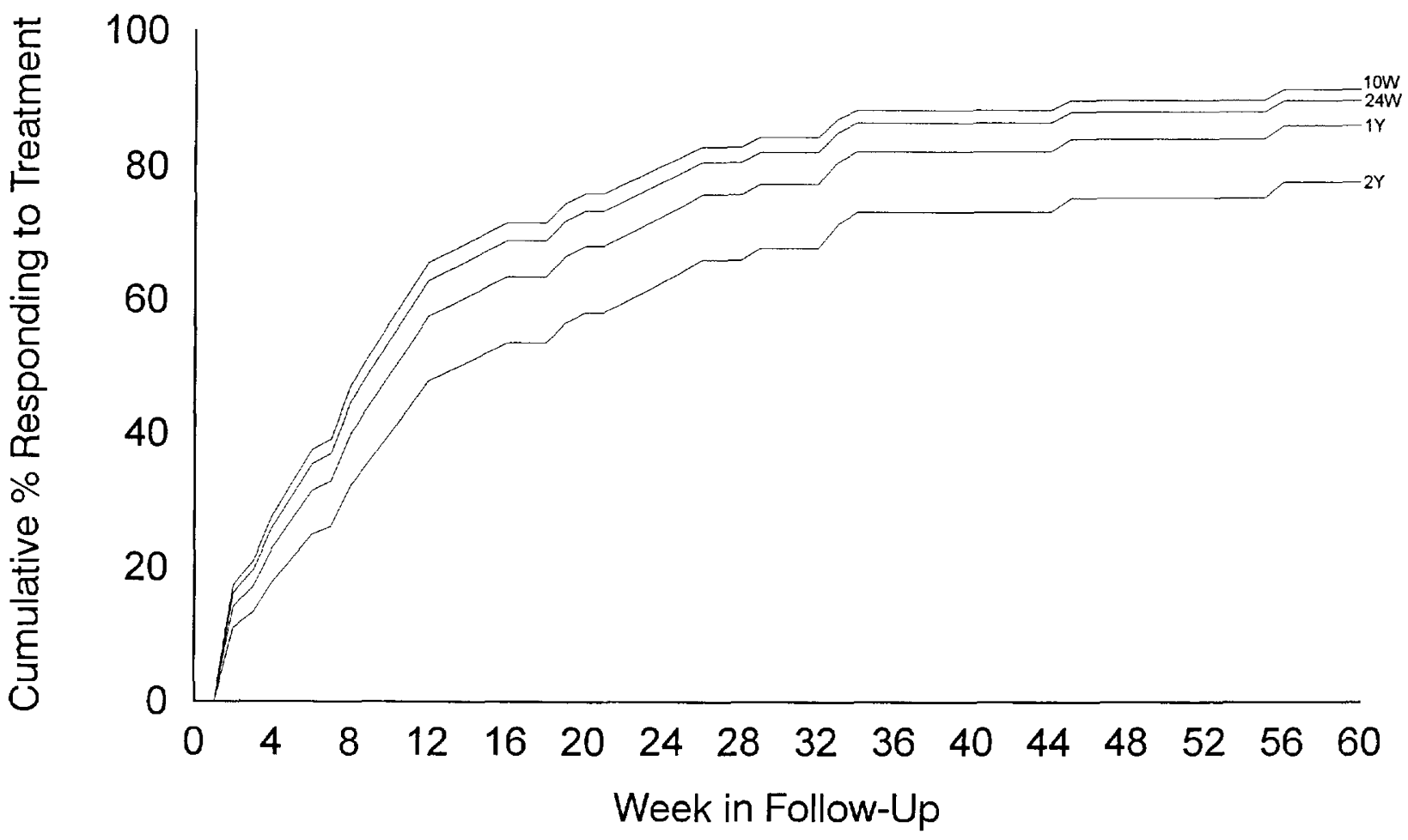

Figure 2. Cumulative percentage of first-episode patients responding to treatment by duration of illness prior to study entry. Abbreviations: 10w, 10 weeks; 24w, 24 weeks; 1 y, 1 year; $2 \mathrm{y}, 2$ years. 
2.3, $p=.14)$. All of the schizoaffectives remitted by week 26, whereas seven schizophrenic patients had not remitted by 52 weeks.

We evaluated the prognostic value of the patients' symptom ratings at two time points: baseline pretreatment and at 20 weeks of treatment. Using the composite of positive and negative symptoms and individual items of the SADS-C + PD and SANS as the independent variables, the time course to remission of patients was projected using a Cox regression analysis. Neither individual symptoms nor ratings of global severity at baseline significantly predicted treatment response. Not surprisingly, as remission was defined largely on the basis of positive symptoms, positive symptom severity at 20 weeks was significantly related to time to remission. Of more interest is the finding that higher levels of specific negative symptoms (affective flattening, alogia) at 20 weeks were associated with longer time to remission. It could be argued that negative symptoms remained high in patients who took longer to remit because they are, to some extent, secondary to persisting positive symptoms. In an effort to disentangle the two symptom constellations, we repeated the analysis of time to remission by negative symptom levels at 20 weeks controlling for the (change in) positive symptom severity at 20 weeks. Affective flattening and alogia remained significant predictors of time to remission $(p<$ .05). In contrast, attentional impairment, a negative symptom likely to be influenced by the level of positive symptoms, was not correlated with time to remission. These results demonstrate the interrelationship between positive and negative symptoms during the acute phase of schizophrenia. When positive symptom levels are high it may be impossible to identify primary negative symptoms, thus the assessment of negative symptoms following positive symptom remission may be more productive.

To examine this further, we classified patients according to criteria for the deficit state, adapted from Carpenter (Mayerhoff et al. 1994). Ten percent of the sample met criteria for the deficit state subsequent to their first episode; $16 \%$ were classified as questionable and $74 \%$ as nondeficit state. No patient with a questionable or definite deficit state had a good or excellent outcome; $33 \%$ had a fair and $67 \%$ a poor outcome, whereas the outcomes for nondeficit state patients were $24 \%$ excellent, $29 \%$ good, $36 \%$ fair, $12 \%$ poor $\left(\chi^{2}=23.4, p=\right.$ $.01)$. These results are consistent with the hypothesis that primary negative symptoms mark a specific pathophysiologic substrate and subtype of schizophrenia (Carpenter et al. 1988).

Plasma HVA was examined at baseline by indwelling catheter serial sample collection and by weekly venipuncture during acute treatment under standardized conditions (Koreen et al. 1994) (see Figure 3). Females had significantly higher HVA levels $(\mathrm{F}=57, p<$
.001). Subsequent analyses controlled for gender. Baseline HVA was not correlated with baseline psychopathology but was associated with residual negative symptoms following remission $(\mathrm{r}=-0.31, p=.049)$. Plasma HVA was significantly increased over baseline for the first 3 weeks of treatment and subsequently declined to, but not below, baseline levels. Baseline HVA predicted time to remission with those having higher levels responding sooner $\left(\chi^{2}=3.7, p=.06\right)$.

Brain MRIs of 62 patients and 42 healthy control subjects were evaluated by visual inspection under blind conditions by two psychiatrists trained in neuroanatomy (Lieberman et al. 1992a). Using operational criteria and conservative classification, a consensus qualitative determination was made as to the presence or absence of abnormal morphology in each of four regions (lateral ventricles, third ventricle, frontal/parietal cortex, medial temporal cortex). Subjects with one or more areas classified as abnormal were called globally abnormal. By this definition patients had significantly higher abnormal ratings than the control group with $31 \%$ of the patients rated definitely abnormal, $36 \%$ questionable, and $33 \%$ normal, whereas the control group was 5\% abnormal, 38\% questionable, and 57\% normal ( $p=.01$ ). The highest prevalence of pathomorphology was in the lateral ventricles followed (in descending order of frequency) by the medial temporal cortex (MTC), third ventricle, and cortex. The prevalence of abnormal ratings was greater in the patients than controls in all four regions. Sixteen patients $(22 \%)$ had one area involved; $13(23 \%)$ had two areas; two (13\%) had three areas, and one had all four areas of involvement. Patients with abnormal morphology, particularly of the third ventricle, took longer to remit (mean/median 42/14 weeks vs 18 / 6 weeks, Wilcoxin stat $=5.7, p=.02$ ) and had a poorer level of outcome than patients with normal morphology.

Twenty-two patients whose first episode remitted subsequently relapsed, and six patients had a second relapse. The treatment regimens that patients had responded to in their prior episode were reinstituted. If patients failed to respond to this, then the treatment algorithm was followed until they achieved remission. We examined the time to remission by episode for the 22 patients who had two episodes and the six patients who had three episodes. The median \pm SE times to remission for the two-episode group were $8.4 \pm 1.3$ weeks for the first and $11.9 \pm 2.3$ weeks for the second episode (Mantel Cox Stat $=3.4, d f=1, p=.06$ ). Whereas by definition all 22 of the patients remitted from their first episode, only 20 have remitted so far from their second; one has gone on to receive clozapine. The median $\pm \mathrm{SE}$ remission times for the six patients who had three episodes were $4 \pm 2.5$ weeks, $7 \pm 1.6$ weeks and $24.1 \pm 2.5$ weeks, respectively (Mantel Cox Stat $=14.1, d f=2, p=$ .001). Thus far, only four of six patients have remitted from the third episode. 


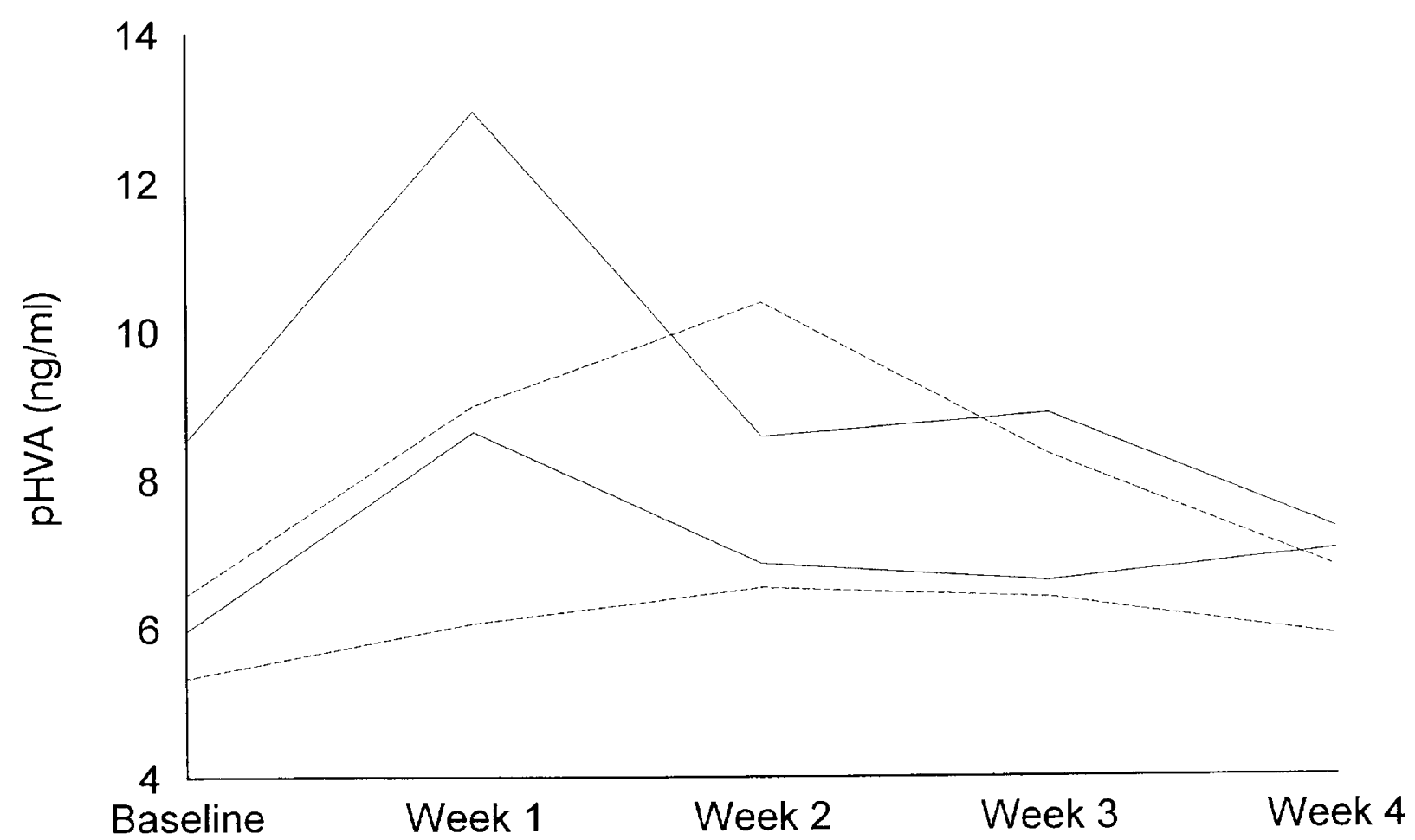

Figure 3. Plasma homovanillic acid (pHVA) level and response during a 4-week period. The top two lines indicate female patients; bottom two lines, male patients; solid lines, patients who met remission criteria (Clinical Global Impression scale score $\leq 2$, and Schedule for Affective Disorders and Schizophrenia score $\leq 3$ on critical psychotic items) by week 4; and dashed lines, patients who did not remit by week 4 . For male nonresponders, $n=8$; male responders, $n=9$; female nonresponders, $n=4$; and female responders $n=6$.

These results are preliminary, and clearly many factors can influence patients' treatment response and vulnerability to relapse. However, there is a clear pattern of decreasing responsiveness to treatment over subsequent episodes of illness. This is more striking considering that some of the patients have not yet responded and in view of the marked differences in the duration of symptoms prior to beginning treatment between the first and subsequent episodes. This is similar to the longitudinal course that has previously been described in major affective disorders (Post and Weiss 1992; Post 1992). These data have several implications. First they suggest that there is progression (i.e., worsening of the illness) across episodes. Second, they indicate that treatment resistance evolves in some patients over the course of their illness and is not an "all or none" phenomenon that is present at the onset. Third, it is possible, though we do not think likely, that they reflect the development of tolerance to the antipsychotic effects of standard neuroleptics.

We have examined the longitudinal course of brain morphology in preliminary analyses of MRIs at baseline and after 18 months of follow-up in the study (Degreef et al. 1991; Waddington and Lieberman 1994). The results indicated that there is no change in the mean volume of the cerebral cortex or lateral and third ventri- cles for the patient or control groups. However, on closer examination of the scatterplots of the data it was apparent that there was some variation in the degree of change in patients' cortical and ventricular volumes. This can be seen in Figure 4, where the scan volumes for the baseline and 18-month follow-up scans are plotted. If patients had no change, their values would fall on the diagonal. If they had an increase or decrease in volume, their values would fall above or below the diagonal. Interestingly, most of the patients that exhibited an increase in ventricular volume and decrease in cortical volume were patients indicated by the letter $\mathrm{N}$ who had a poor outcome in terms of not recovering from their first episode or rapidly relapsing. This is shown by the bar graph that is inset in the scatterplot figure. Figure 5 illustrates the relationships between outcome, as reflected by time to remission, and the ventricular volumes at baseline and follow-up and the change values. Patients who had large ventricles at study entry had a poorer treatment outcome than patients who had smaller ventricles. Patients who entered the study with large ventricles or small ventricles that increased in volume by the follow-up MRI had a poorer outcome than patients with small ventricles that do not increase in volume. Given the short timeframe of the follow-up (18 months), the variability of when patients entered the 

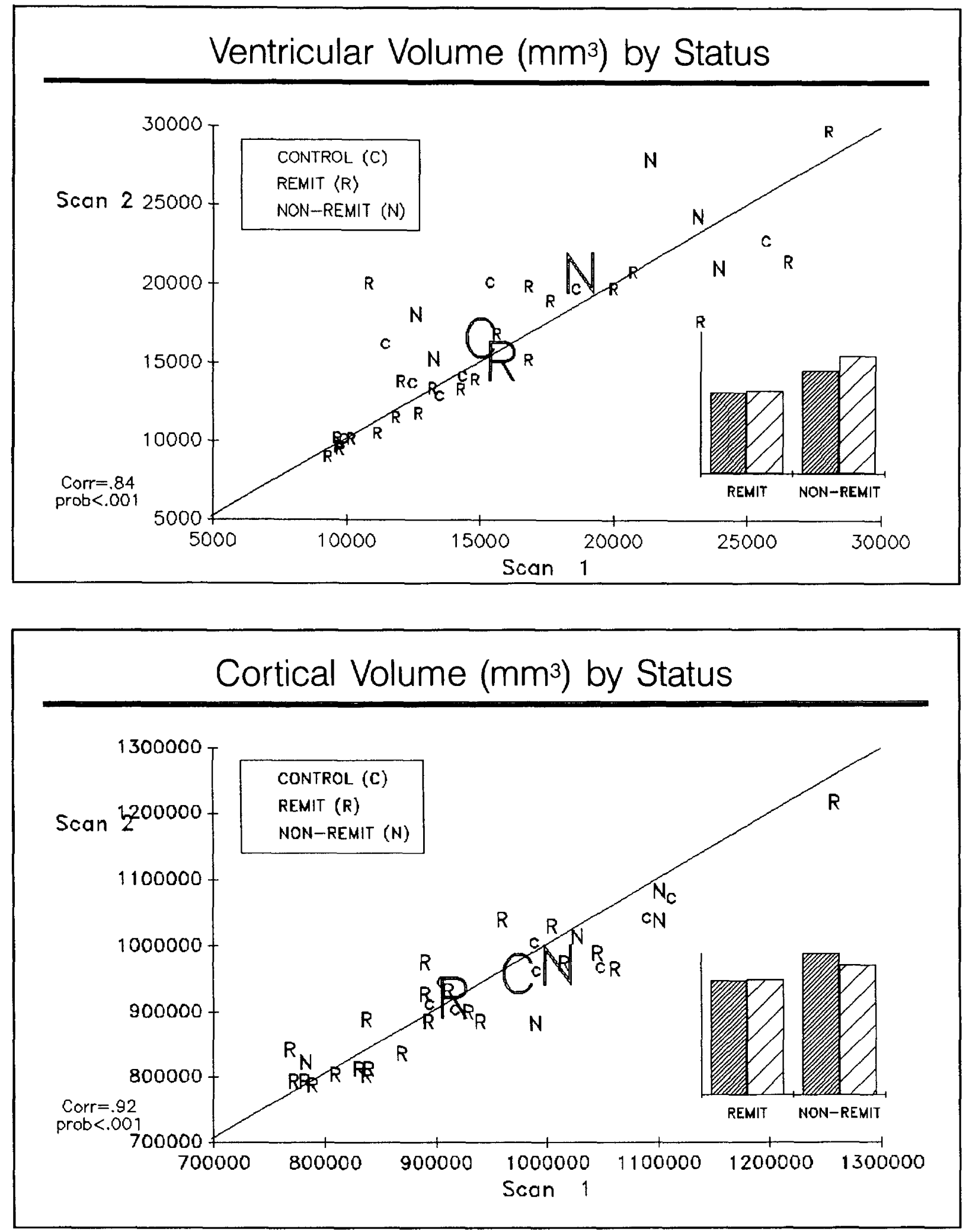

Figure 4. Scatterplot depicts the volume in cubic mm for cerebral cortex and the ventricular system at baseline (scan 1) and follow-up (scan 2) scans. The patient sample was classified into patients with good (R) and poor (N) treatment outcome. The bar graph inset indicates the volumes for each subgroup of patients for both scans. 

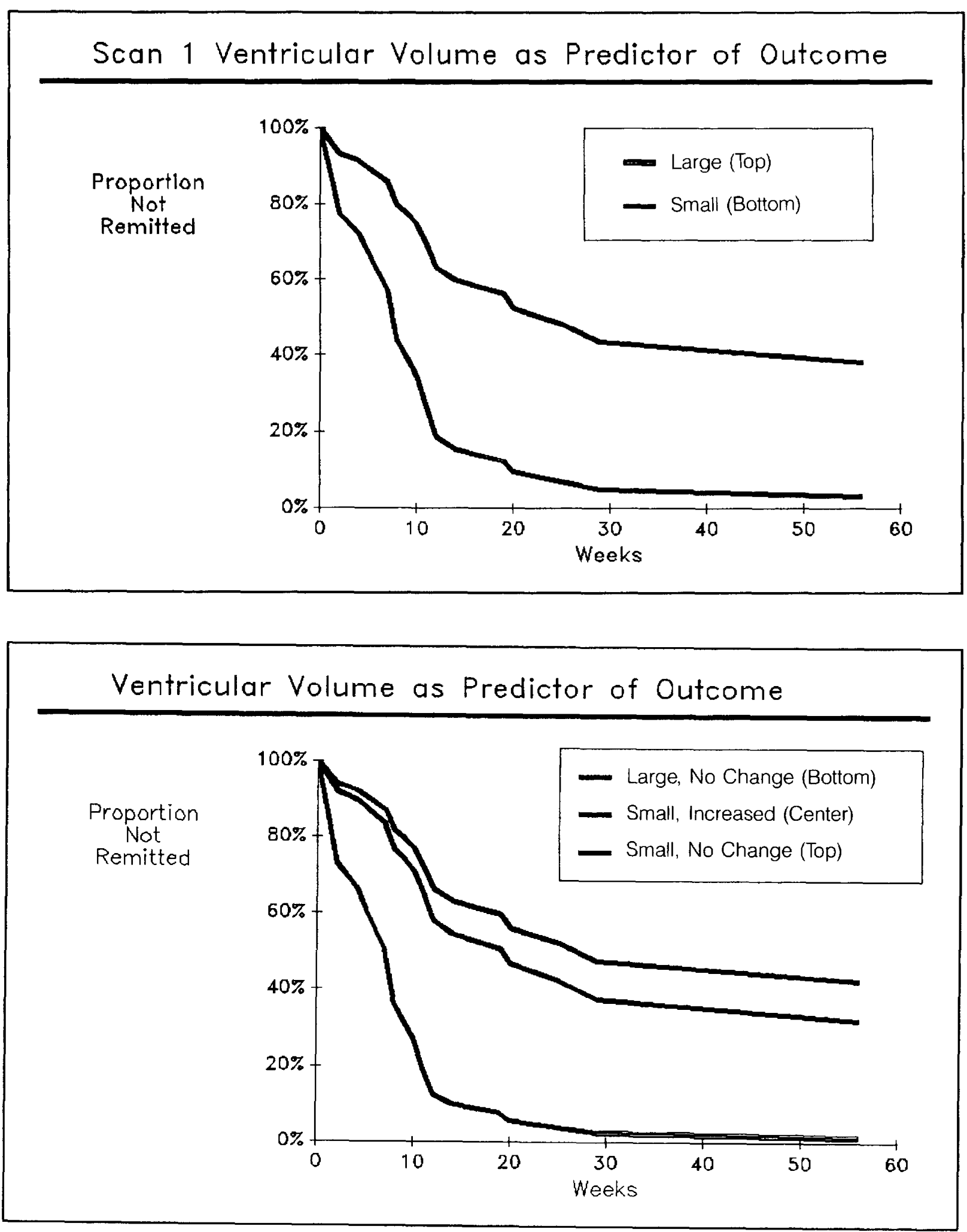

Figure 5. The top and bottom figures illustrate the outcome of patients from their first episode in the context of the standardized protocol. In the top figure the sample has been divided into patients with large or small ventricles. Patients with small ventricles have a higher rate of remission. The lower figure depicts that patients with small ventricles at baseline and do not increase over the scanning interval have the best outcome. While patients with large ventricles at baseline and patients with small ventricles that increase in size have worse outcomes. 
study in relation to their illness durations, and the small sample size, these results are clearly preliminary. However, they are consistent with the results of the early pneumoencephalographic findings of Haug (1962) and Huber (1957) as well as more recent computed tomography (CT) and MRI studies and suggest that the question of whether the neuropathology of schizophrenia is progressive requires further investigation (Illowsky et al. 1988; Kemali et al. 1989; Woods et al. 1990; Degreef et al. 1991).

\section{DISCUSSION}

These results have two major implications. First, that the treatment outcome of first-episode schizophrenia is quite good in that most patients recover or at least achieve a substantial degree of symptom remission. However, over the course of their illness and in the context of subsequent episodes of psychotic exacerbation, they may experience some decrease in their treatment response, either due to progression of their illness or the development of tolerance to antipsychotic treatment effects. Second, the heterogeneity of treatment outcome is, to some degree, due to specific clinical and biologic variables. These include factors that appear to be trait specific (e.g., gender, deficit state) and others that are state dependent (e.g., duration of psychosis, pHVA). It is unclear whether these variables are aspects of discrete subtypes of schizophrenia (McGlashan and Fenton 1991) or represent dimensional measures of pathology within the broad context of a unitary disease entity (Carpenter and Buchanan 1989; Crow 1990).

These results also bear on the question of whether schizophrenia is wholly a neurodevelopmental disorder as has been suggested (Weinberger 1987; Murray et al. 1987 ) or may also involve a (neuro)degenerative process as well (Lieberman et al. 1990; Wyatt 1991). Clearly, the results of the longitudinal study of brain morphology must be regarded as preliminary, and several points can be made that qualify their interpretation. First, morphometric assessment of brain morphology is highly method dependent and error prone, so great emphasis must be placed on the development and use of reliable and valid methods. Second, if there is neuropathologic progression in schizophrenia, it is likely to be of a small magnitude and to occur over a relatively brief and nonlinear time period. Thus, the timing of when patients are ascertained and studied becomes critical. In our study patients were entered after a range of prior illness duration (52 weeks on average) and reexamined after 18 months. Thus, they could have been ascertained after the putative progression had already occurred or restudied (at 18 months) before any progression had yet occurred. Moreover, given the measurement variance and the small magnitude of change, it is likely that large sample sizes will be required to identify this process (if it develops). Nevertheless, the association between change in brain morphology in the direction that would be predicted (i.e., ventricular enlargement and cortical volume reduction) and treatment outcome is consistent with the hypothesis that schizophrenia is a degenerative disease in clinical and neurobiological terms. Additional studies are required to answer this question definitively.

\section{ACKNOWLEDGMENTS}

This study was supported by grants from the National Institute of Mental Health (MH41646), a Research Scientist Development Award (MH00537) to Dr. Lieberman and the Mental Health Clinical Research Center for the Study of Schizophrenia at Hillside Hospital (MH41960).

\section{REFERENCES}

Bilder RM, Wu H, Bogerts B, Degreef G, Ashtari M, Alvir JMJ, Snyder PJ, Lieberman JA (1994): Absence of regional hemispheric volume asymmetries in first-episode schizophrenia. Am J Psychiatry 151(10):1437-1447

Carpenter WT, Buchanan RW (1989): Domains of psychopathology relevant to the study of etiology and treatment of schizophrenia. In Schultz SC, Tamminga CT (eds), Schizophrenia: Scientific Progress. New York, Oxford Press

Carpenter WT, Heinrichs DW, Wagman AMI (1988): Deficit and non-deficit forms of schizophrenia: The concept. Am J Psychiatry 145:578-583

Chakos MH, Lieberman JA, Bilder RM, Lerner G, Bogerts B, Degreef G, Wu H, Ashtari M (1994): Increase in caudate nuclei volumes of first episode schizophrenic patients taking antipsychotic drugs. Am J Psychiatry 151(10): 1430-1436

Chakos MH, Mayerhoff DI, Loebel AD, Alvir JM, Lieberman JA (1992): Incidence and correlates of acute extrapyramidal symptoms in first-episode schizophrenia. Psychopharmacol Bull 28(1) 81-86

Crow TJ, DeLisi LE, Johnstone EC (1990): In reply...A locus closer to the telomere? Br J Psychiatry 156:416-420

Crow TJ, MacMillan JF, Johnson AL, Johnstone EC (1986): A randomised controlled trial of prophylactic neuroleptic treatment. Br J Psychiatry 428:120-127

Degreef $G$, Ashtari M, Bogerts B, Bilder RM, Jody DN, Alvir J, Ma J, Lieberman JA (1992): Volumes of ventricular system subdivisions measured from magnetic resonance images in first-episode schizophrenic patients. Arch Gen Psychiatry 49:531-537

Degreef G, Ashtari M, Wu H, Borenstein M, Geisler S, Lieberman J (1991): Follow-up MRI study in first episode schizophrenia. Schizophr Res 5:204-206

Haug OJ (1962): Pneumoencephalographic studies in mental disease. Acta Psychiatry Scand 165(suppl): 1-114 
Huber G (1957): Pneumoencephalographische und psychopathologische Bilder bei endogen Psychosen. Springer, Berlin

Illowsky BP, Juliano AM, Bigelow LB, Weinberger DR (1988): Stability of CT scan findings in schizophrenia: Results of an eight-year follow-up study. J Neurol Neurosurg Psychiatry 51:209-213

Koreen A, Lieberman J, Alvir J, Chakos M, Loebel A, Cooper T, Kane J (1994a): Relation of plasma fluphenazine levels to treatment response and extrapyramidal side effects in first episode schizophrenic patients. Am J Psychiatry 151:35-39

Koreen AM, Lieberman J, Alvir J, Mayerhoff D, Loebel A, Chakos M, Amin F, Cooper T (1994b): Plasma homovanillic acid in first episode schizophrenia: Psychopathology and treatment response. Arch Gen Psychiatry 51:132-138

Koreen AR, Siris SG, Chakos M, Alvir J, Mayerhoff D, Lieberman J (1993): Depression in first episode schizophrenia. Am J Psychiatry 150:1643-1648

Lieberman JA, Alvir JMJ, Woerner M, Degreef G, Bilder R, Ashtari M, Bogerts B, Mayerhoff DI, Loebel A, Levy D, Hinrichsen G, Szymanski S, Chakos M, Borenstein M, Kane JM (1992a): Prospective study of psychobiology in first episode schizophrenia at Hillside Hospital: Design, methodology and summary of findings. Schizophr Bull 18(3):351-371

Lieberman J, Bogerts B, Degreef G, Ashtari M, Alvir J (1992b): Qualitative assessment of brain morphology in acute and chronic schizophrenia. Am J Psychiatry 149(6):784-794

Lieberman JA, Jody D, Alvir JMJ, Ashtari M, Levy D, Bogerts B, Degreef G, Mayerhoff D, Cooper T (1993a): Brain morphology, dopamine, and eye tracking abnormalities in first episode schizophrenia: Prevalence and clinical correlates. Arch Gen Psychiatry 50:357-368

Lieberman J, Jody D, Geisler S, Alvir J, Loebel A, Szymanski S, Woerner M, Borenstein M (1993b): Time course and biological correlates of treatment response in first episode schizophrenia. Arch Gen Psychiatry 50:369-376

Lieberman JA, Kinon BJ, Loebel AD (1990): Dopaminergic mechanisms of idiopathic and drug-induced psychosis. Schizophr Bull 16(1):97-110

Lieberman JA, Koreen A (1993): Neurochemistry and neuroendocrinology of schizophrenia. A selective review. Schizophr Bull 19(2):371-429

Lieberman JA, Sobel S (1993): Predictors of treatment response and course of schizophrenia. Curr Opin Psychiatry 6:63-69

Loebel AD, Lieberman JA, Alvir JMJ, Mayerhoff DI, Geisler SH, Szymanski SR (1992): Duration of psychosis and outcome in first episode schizophrenia. Am J Psychiatry 149:1183-1188

May PR, Tuma AH, Dixon WJ (1981): Schizophrenia: A follow-up study of the results of the five forms of treatment. Arch Gen Psychiatry 38:776-784

Mayerhoff DI, Loebel AD, Borenstein M, Szymanski SR, Geisler SH, Alvir JMJ, Lieberman JA (1994): The deficit state in first-episode schizophrenia. Am J Psychiatry 151(10):1417-1422

McGlashan TH (1988): A selective review of recent North American long-term follow-up studies of schizophrenia. Schizophr Bull 14(4):515-542

McGlashan TH, Fenton WS (1991): Classical subtypes for schizophrenia: Literature review for DSM-IV. Schizophr Bull 17:609-632

Murray RM, Lewis SW (1987): Is schizophrenia a neurodevelopmental disorder? Br Med J 295:681-682

Post RM (1992): Transduction of psychosocial stress into the neurobiology of recurrent affective disorder. Am J Psychiatry 149:999-1010

Post RM, Weiss SRB (1992): Endogenous biochemical abnormalities in affective illness: Therapeutic versus pathogenic. Biol Psychiatry 32:469-484

Szymanski S, Lieberman JA, Alvir JM, Mayerhoff D, Loebel A, Geisler S, Chakos M, Koreen A, Jody D, Kane J, Woerner M, Cooper T (1995): Gender differences in onset of illness, treatment response, course, and biologic indexes in first-episode schizophrenic patients. Am J Psychiatry 152:698-703

Waddington JL, Lieberman JA (1994): New insights into clinical issues in schizophrenia. Psychopharmacol 8:65-66

Weinberger DR (1987): Implications of normal brain development for the pathogenesis of schizophrenia. Arch Gen Psychiatry 44:660-669

Woods BT, Yurgelun-Todd D, Benes FM, Frankenburg FR, Pope HG, McSparren J (1990): Progressive ventricular enlargement in schizophrenia: Comparison to bipolar affective disorder and correlation with clinical course. Biol Psychiatry 27:341-352

Wyatt RJ (1991): Neuroleptics and the natural course of schizophrenia. Schizophr Bull 17:325-351 